\title{
Developing the UNICEF Malawi school handwashing program
}

\author{
Dr Joy Parkinson ${ }^{1}$ \\ Mr Philip C. Mkandawire ${ }^{2}$ \\ Dr Timo Dietrich ${ }^{1}$ \\ Ms Abi Badejo ${ }^{1}$ \\ Dr Mohammad Kadir ${ }^{1}$ \\ Ms Violet Tembo ${ }^{3}$ \\ ${ }^{1}$ Social Marketing @ Griffith, Griffith University, Brisbane Australia \\ ${ }^{2}$ PSI Malawi \\ ${ }^{3}$ UNICEF Malawi
}

\begin{abstract}
Diarrhea is one of the major causes of morbidity and mortality among children and immune-compromised individuals in Malawi. Handwashing with Soap (HWWS) is one of the most cost-effective health interventions to prevent diarrhea. UNICEF Malawi has adopted a social marketing approach to achieve large scale behavioral change for HWWS. The study, commissioned by UNICEF Malawi, was developed by PSI Malawi and Griffith University and conducted by PSI Malawi.

Formative research insights using two research studies are presented including observations at 30 primary schools in terms of HWWS behaviour. Second, Key Informant Interviews with school administrators and staff members were conducted to understand HWWS Motivation, Opportunity and Ability (MOA) factors. This study found less than half of the assessed schools had hand washing facilities.

Structural barriers that prevent school children from practicing HWWS were identified including a lack of financial resources to construct permanent hand washing facilities in schools. Many schools also experience a lack of support from the community as citizens are not aware of the benefits of HWWS. Changes to school and community infrastructure are required to facilitate the adoption of the behavior. Supporting activities to encourage school children to practice HWWS and reinforcement strategies to sustain the behavior over time should also be implemented. School children can then become change agents for HWWS by reinforcing the behavior at home thereby contributing to the achievement of the national objectives to reduce diarrhea and leading to improved health and wellbeing for communities in Malawi.
\end{abstract}

\section{Introduction}

Malawi is a low income country in Sub-Saharan Africa. The large majority of the population (82\%) still lives in rural areas (World Bank, 2017). Sixty three per cent of Malawians live on less than US\$2 per day. Malawi has the highest malnutrition prevalence in the South African Development Community (SADC) region. Further, Malawi is strongly marked by demographic pressure, a high prevalence of HIV/AIDs, striking poverty and very low human and social development (World Bank, 2017). There are an estimated 122 children per 1, 000 who die before the age of five. There were 5, 405 primary schools in Malawi in 2012; 5, 267 of which are public schools (EMIS, 2013). 
Diarrhea is one of the major causes of morbidity and mortality among children and immune-compromised individuals in Malawi (National Statistical Office (NSO) \& ICF Macro, 2010). On average, a Malawian child experiences diarrhea six times per year, and 20 percent of deaths in infants and children under the age of five are due to diarrheal disease (National Statistical Office (NSO) \& ICF Macro, 2010). Public health interventions on hygiene education and safe water supply in Malawi have increased access to safe water with 79 percent of households having access to piped water, public tap, borehole or a protected well or spring. Relative to several other sub-Saharan countries, Malawi has a high level (75 percent) of access to some form of basic excreta disposal facilities (latrines). However, 11 percent of the population has no toilet facility and consequently practices open defecation. Despite the increased access to safe water, diarrhea continues to be a major health problem in Malawi. Handwashing with Soap (HWWS) is the single-most cost-effective health intervention to prevent diarrhea (Bhutta et al., 2013; Jamison et al., 2006).

HWWS is effective because it breaks the transmission cycle by removing pathogens that infect people via hands that have been in contact with faeces and other body secretions, contaminated drinking water, unwashed raw food and unwashed utensils or smears on clothes (Humphrey, 2009). Systematic reviews have consistently shown HWWS is effective at reducing diarrheal disease and can reduce the risk of diarrhea by around 30\% (EjemotNwadiaro, Ehiri, Arikpo, Meremikwu, \& Critchley, 2015). Reports from the World Health Organization (2008) further show HWWS interventions can cut diarrheal disease incidence by nearly half, reduce the rate of respiratory infections by about 25 percent, and reduce the incidence of skin diseases, eye infections (e.g. trachoma), intestinal worms and enteric viruses. Numerous interventions have been implemented to reduce the incidence of diarrhea among children and other vulnerable groups in Malawi. While often passed over for more elaborate infrastructure interventions, it has been argued HWWS is the single most cost effective public health intervention (Bhutta et al., 2013; Jamison et al., 2006). It only takes \$3.35 to yield one unit (equivalent to one year) improvement on the Disability-Adjusted Life Years (DALYS) scale (National Statistical Office (NSO) \& ICF Macro, 2010; World Health Organization, 2008). HWWS is therefore an important public health approach to reduce the burden of diseases associated with poor hygiene (Watson et al., 2017).

Despite evidence for HWWS, efforts to reinforce this behavior have met with limited success in Malawi (UNICEF, 2012) due to most interventions relying on uncoordinated promotional activities both at a national and local level. Thus the proportion of the population practicing HWWS at critical times (e.g. after toileting or before eating) remains very low, with studies indicating only three percent of the population are practicing the behavior (UNICEF, 2012). To combat this problem and achieve large scale behavioral change, UNICEF Malawi has adopted a social marketing approach. Developing a rigorous evidence-base is essential to support the rollout of social marketing programs. Formative research is a key criterion for social marketing program design (Andreasen, 2002; Kubacki \& Rundle-Thiele, 2016). The purpose of this paper is to provide formative insights on influencing HWWS behaviour in schools, households and the wider community as well as the potential of school children becoming change agents. The insights will be used to develop a pilot social marketing program to be undertaken in Malawian schools as part of the National Hand Washing Campaign. The research will also support government, non-government and private sector to develop evidence-based programs during their engagement in the National Hand Washing Campaign. Furthermore, this research answers calls to go beyond self-report methods in social marketing by employing a mix of approaches including observations and interviews to enable triangulation of data sources (Carins et al., 2016). 


\section{Background}

Water, Sanitation and Hygiene (WASH) interventions have been shown to reduce diarrhea and other intestinal infections and are important in promoting optimal child development in developing countries (Piper et al., 2017). The school remains an important context for behavior change and knowledge on WASH interventions (Blanton et al., 2010; Jasper, Le, \& Bartram, 2012; Joshi \& Amadi, 2013). Some studies have demonstrated malnutrition affects school enrolment (Glewwe \& Jacoby, 1995), whilst school-based WASH interventions improve attendance (Freeman et al., 2012; Talaat et al., 2011). HWWS interventions are one specific type of a range of WASH interventions (Piper et al., 2017) and they can deliver positive behavioral outcomes. For example, a school-based handwashing program has shown a decrease both to absenteeism and length of absence (Bowen et al., 2007) and improved handwashing practice (Rosen et al., 2006). Furthermore, supply, improvement and maintenance of existing facilities is key to reducing episodes of illness (Koopman, 1978) and encouraging children to practice HWWS. There remains however limited evidence of HWWS programs in schools in low and middle-income countries (Watson et al., 2017).

Both the Malawi Vision 2020 Plan (National Economic Council, 1998) and Malawi National Health Plan (2011-2016) (Malawi Ministry of Health, 2011) emphasise health improvement. Desired health outcomes of the five-year National Health Plan include reduced risk factors to health and improved equity and water, sanitation, efficiency in the delivery of quality Essential Health Package (EHP) services. Specifically, these desired outcomes emphasise the creation of "healthy settings programs (workplaces, schools, and communities), and food safety interventions" (UNICEF, 2012). One of these key initiatives is the creation of the National Hand Washing Campaign which supports government, nongovernment and the private sector to develop evidence-based programs to combat diarrhea as one of the major causes of morbidity and mortality in Malawi. The current project and accompanying baseline and end line studies, are in line with the goals of both of these national plans. Furthermore, this project will build upon current progress achieved by the Government of Malawi in collaboration with the national and district WASH partners such as UNICEF to ensure the planned activities complement, and not duplicate, the work of government and other agencies in sanitation and hygiene. Accordingly, the primary objective of this social marketing program is to increase the number of school children practicing HWWS. To reflect this objective, children in primary schools form the key target group. School children are accessible through their school and their habits may be more easily moulded at a young age (Loewenstein, Price, \& Volpp, 2016; Verplanken \& Wood, 2006). School children may also serve as change agents by reinforcing HWWS behavior within the home environment. Social marketing scholars have called for research to extend beyond the individual to include the environment where the behaviour occurs (Domegan et al. 2016, Parkinson et al., 2016; Brennan et al., 2014). Given the context of the current study is schools, and HWWS programs are funded by governments, this study is guided by a socioecological assessment to examine the individual, social, and environmental factors that influence HWWS behaviour (Almosa et al., 2017). Therefore, to better understand Malawian school children's current HWWS behaviour, this formative research is guided by the MOA framework to expand the enquiry beyond the individual to consider the upstream, midstream and downstream forces of behavior change (Parkinson et al., 2016).

\section{Motivation, opportunity and ability (MOA)}

The original MOA framework posits the degree to which individuals process information is based on three factors: motivation, opportunity, and ability (Jaworski \& 
MacInnis, 1989). Over time, however, the outcomes associated with the MOA framework have been broadened from consumer information processing to include a multitude of behaviors. More recently, Binney, Hall and Oppenheim (2006) use the framework to predict environmental behavior and Willmott and Parkinson (2017) use MOA to explore healthy eating and physical activity behaviors. This literature base proposes individuals will engage in a particular behavior when their motivation, ability and opportunity are sufficiently high.

Motivation has been defined as goal-directed arousal (Park \& Mittal, 1985). Based on the MOA theory, motivation incorporates readiness, willingness, interest, and desire to engage in information processing (MacInnis et al., 1991) or in a particular behavior (Morel et al., 1997). Personal relevance, goals and needs, perceived risk, and consistency with existing attitudes have been proposed to impact motivation (Hoyer \& MacInnis, 1997). On the other hand, opportunity reveals the extent to which a situation is conducive to achieving a desired outcome. That is, the extent to which external circumstances, infrastructure or the environment facilitates or inhibits a particular behavior (Parkinson et al., 2016). Last, ability refers to the extent to which individuals have the necessary skills or proficiencies to make an outcome happen, for example, knowledge, intelligence and money (Hoyer \& MacInnis, 1997). Thus, it is the individual's capability or skill to engage in a certain behavior and achieve its referent goal (Morel et al., 1997). Past experience, subjective knowledge and a sense of situational competence has also been linked with ability (Dholakia \& Bagozzi, 2002; MacInnis et al., 1991).

A review of hand washing research in Malawi revealed no evidence of the opportunity, ability and motivation of school children to wash their hands with soap. The MOA framework is employed in this study for two primary reasons. First, the MOA framework is proposed to capture factors influencing behavior at the individual, social and environmental level (Parkinson et al., 2016) through the concepts of motivation, opportunity and ability (Morel et al., 1997). Second, the parsimonious MOA framework is a general framework shown to be applicable to a range of behaviors including social behaviors (see Binney et al., 2003; Binney et al., 2006; Willmott \& Parkinson, 2017), thus it is useful for HWWS. The following research questions guided this research:

RQ1: How much opportunity do school children have to perform HWWS?

RQ2: What are the school management perceptions of school children's motivations, opportunities, and abilities to perform HWWS behavior?

\section{Context and Process}

\section{Method}

Commissioned by UNICEF Malawi, the study was developed by PSI Malawi and Griffith University and conducted by PSI Malawi. Ethical clearance was obtained through Griffith University. The formative research featured two studies; Study 1: Observations of primary school children HWWS behaviour. Consent to observe handwashing stations was given by school administrators at each school participating in the study and Study 2: Key Informant Interviews (KIIs) were conducted with one school administrator and one staff member from each included school to understand HWWS MOA factors affecting provision of regular access to handwashing facilities and soap to their students. The baseline study was undertaken in ten schools from each of three Malawian school districts: Nkhatabay, Salima and Mangochi ( $\mathrm{n}=30$ schools). Next, the method, results, and discussion are presented first for Study 1, followed by Study 2. 


\section{Study 1: Observations}

\section{Method}

Structured observations of handwashing behaviour were used to answer research question 1 , how much opportunity do school children have to perform HWWS? All students (ages 6-12 years) who used the toilet during tea and lunch breaks were observed for HWWS during a one day visit to the schools. Data collection occurred in January and February, 2015. Four research assistants observed student behavior in cases where handwashing stations were open and their presence was not easily detected, for example, to the side of handwashing facilities. Observers were split between male and female toilets. Observations occurred prior to KIIs to eliminate bias affecting handwashing behavior. School facilities were first assessed by informants to determine the availability of soap and water at handwashing stations, and the locations of handwashing stations in relation to toilets or places within the school complex where school children frequently eat.

An observational approach was used for understanding school children's current handwashing behavior. Using observations allows the researcher to record what individuals truly do, not what they claim to have done, which is important in contexts where social desirability may impact reporting (e.g. handwashing) (Rundle-Thiele, 2009). Structured covert observations, which involve the observation and recording of actual behavior were used for this study (Almosa, Parkinson, \& Rundle-Thiele, 2017). An observation protocol and coding sheet was employed to record the observations of individual handwashing behavior as they used the toilets. The coding sheet which employed the use of tally marks, allowed the observers to collect the observation data in an efficient manner. All observations were conducted by four trained research assistants. The collected data were then entered into an access database. Data quality was checked before exporting to SPSS for analysis.

\section{Results and Discussion}

In total 3,675 primary school children (1,900 girls; 1,775 boys) were observed in terms of behavior (handwashing vs. no handwashing, one hand vs. two hands) and method (water or water and soap). The school children observed were from the Lower (Standard 1 to 4) and Upper (Standard 5 to 8) classes, with 59\% from Lower and 41\% from Upper (see Table 1). Where present, handwashing facilities outside of one female toilet and one male toilet at each of the schools were observed.

\section{Insert Table 1 here}

This study found less than half (41.7\%) of the assessed schools had hand washing facilities. In Nkhatabay district, 13 hand washing facilities were observed at the 10 schools and 12 were observed in Salima district, but no hand washing facilities were observed in Mangochi district. The most common hand washing facility observed was the bucket (48\%). Sinks and improvised taps were the next most common type of handwashing facility observed, and $16 \%$ of schools overall had these types of facilities. Piped water (8\%), water tanks (8\%), and suspended plastic bottles (4\%) were less common. Overall, 64\% of the handwashing facilities observed were outside the toilets, $28 \%$ near the classroom and $8 \%$ were found inside the toilet building (outside of toilet stalls). In $48 \%$ of schools, handwashing facilities were within one to five metres of the toilets. However, others were between 51 and 100 metres from the toilets which may be a barrier to students using the facilities at the appropriate times and place. The majority (76\%) of handwashing facilities were found to be clean, while $12 \%$ were 
somewhat dirty, $8 \%$ were very dirty and $4 \%$ were not functional at all. Toilets on the other hand, were not found to be as clean as the handwashing facilities with $38.3 \%$ found to be somewhat dirty, $33.3 \%$ were clean and $28.3 \%$ were found to be very dirty.

The study also found $56 \%$ of the handwashing facilities had water and $76 \%$ of these facilities had clean water. Only two (3.33\%) out of 60 toilets (males and females) observed had soap for hand washing at the time of the visit. Bars of soap were found in both schools where soap was available for handwashing. No handwashing facilities were found inside the toilet stalls or toilets themselves. Water was found in only slightly more than half (56\%) of all handwashing facilities observed in the study, meaning $44 \%$ did not have any water for students to wash their hands despite having the facility available. In locations where water was found, it was clean in all cases. More than half of schools (18) had boreholes to provide water for the school including six in Mangochi, seven in Nkhatabay and five in Salima.

Across all districts, rates of handwashing observed were very low. Students were observed at set times, namely during tea and lunch breaks. Overall, 85\% of primary school children failed to wash their hands before eating and after using the toilet; while $14 \%$ of the observed students washed their hands with water only but did not use soap. In the Mangochi district, all students observed failed to wash their hands as there were no handwashing facilities found in any of the ten primary schools. Among the students who did wash their hands at handwashing facilities, nearly all used water only, which was unsurprising given only two observed handwashing facilities provided soap. Significant difference in handwashing behavior was also found between boys and girls $\chi^{2}(1, n=3,675)=30.52, \mathrm{p}<.001$. In Nkhatabay, $76 \%$ of boys failed to wash their hands, while the same was true for only $67.8 \%$ of girls.

\section{Study 2: Key Informant Interviews}

\section{Method}

Key Informant Interviews (KIIs) were conducted to answer research question 2, what are the school management perceptions of school children's motivations, opportunities, and abilities to perform HWWS behavior? KIIs interviews were transcribed and thematically analysed. In total, 60 KIIs were conducted, with one school administrator and one member of staff from each participating school in the three defined study districts. Several questions were posed to the administrators and teachers at each school regarding prior hand washing programs and their successes and challenges, level of motivation about the new HWWS program, and any challenges they foresee for the new program.

Nvivo software was used to assist in the management of data. Data analysis followed a systematic process of transcript-based analysis as summarized by Parkinson, Gallegos \& Russell-Bennett (2016). This was supplemented by iteratively examining the analysis at the end of each step. This form of analysis provides broad definitions and general boundaries of key constructs while identifying and evaluating linkages between such constructs. As such, this process employed both inductive reasoning (Lincoln \& Guba, 1985) and constant comparative methods (Martin \& Turner, 1986).

\section{Results and Discussion}

\section{Motivations}


Students need to be informed of the benefits and importance of handwashing with soap in order for them to be motivated to wash their hands after using the toilet and before eating. Consistent with previous research on habit formation (Verplanken \& Wood, 2006), teachers noted habits take time to form and handwashing behavior needs to be reinforced over time to allow students to form positive habits.

"...when you give something to a kid, it takes time for them to realize how important the thing is to them. So we are busy teaching them the importance of using the facilities we place at the toilets." Head Teacher, Nkhatabay District.

This study found several schools use prefects or school student leaders to motivate the students to wash their hands. Prefects are given extra responsibility to help positively influence their classmates. Using peers to encourage school children to wash their hands reinforces a norm amongst classmates (Perkins, 2003) that helps them to develop healthy habits. School children then better understand the risks of using the toilet without washing their hands properly after, and then consuming food. These habits can then be taken into the home environment allowing school children to become change agents by influencing the norm of HWWS among their families.

"For them to make it a habit, we tell them that they eat feces... so they make it a habit that before they eat anything, they wash their hands. So the pupils believe in monitoring each other, they make sure if a pupil goes out of class to the toilet, they go straight to wash their hands. As they monitor each other, they are able to tell us if one of them hasn't washed their hands. By doing so, the pupils get used to it and it helps the pupils understand that they are supposed to go straight to the tap to wash their hands after using the toilet.” Teacher, Mangochi District.

"We have selected class leaders who take the hand washing facilities, put water in them and put them at every class with soap as well. So pupils wash hands after using the toilet. Teacher, Salima District.

Despite the efforts of schools to emphasize handwashing, the current strategies are not effective in changing school children's behavior. School children do not understand the necessity of handwashing since they do not practice the behavior at home even though they know they've been told to do so in school.

"The major challenge was reluctance. The pupils felt the facilities were of no importance maybe because in their home they are not used to washing hands. I believe there is big problem in our communities of that people don't value the importance of washing hands. Therefore, that habit of not washing hands, which they inherited from home, also prevailed here at school. They didn't see the importance of washing hands." Teacher, Salima District

\section{Opportunity}

Using the MOA framework to analyse the responses from school managers to explore the opportunities available, the environmental strategies included schools providing equipment (buckets, water bottles, and soap) to be used for handwashing. Teachers were resourceful in creating handwashing facilities when school infrastructure was insufficient.

"Aaah, the buckets are inadequate and that's why we try to make additional resources by using those bottles because some of the buckets are used for drinking water and others for washing hands. ” Head Teacher, Nkhatabay District 
Financial constraints were found to have a significant impact on the school infrastructure necessary for hand washing, including handwashing stations and toilets, as well as soap and buckets for handwashing. Without sufficient funds, schools are unable to undertake the necessary maintenance of facilities or the regular provision of soap. The three main financial issues identified were a lack of funds to purchase handwashing equipment including soap, lack of permanent handwashing facilities due to funding and an inadequate number of toilets due to the delay in funding.

"The money that the school committee collects for maintenance of some structures at the school isn't enough to cater for buying the soap but we informed them that there is need for soap at the toilets. Head Teacher, Salima District.

"Termites also destroy the stands constructed. If we had a source of income we would have just constructed the stands for the taps using cement so that we can just pour water inside and they can use the tap. But we fail to do so because of lack of money." Head Teacher, Nkhatabay District

Teachers use grants and other funds to finance the purchase of soap and buckets for school handwashing facilities or toilets. Several organizations including the Livingstonia Synod Program (LISAP), Canadian Physician Aid Relief (CPA), USAID, GTZ, Save the Children, World Vision, Mother Group, and the Malawi Government, have sponsored handwashing facilities in some schools. However, without regular access to soap, even if school children know they should wash their hands with soap after toileting, they are unable to this in turn prevents them from practicing HWWS behavior. Water is also scarce in the schools further preventing students from HWWS.

However, in the Mangochi district where there was no handwashing behavior or handwashing facilities observed, Health Surveillance Assistants teach schools that instead, ashes can be used to de-germ hands after using the toilet and before eating.

"We are working with the Health Surveillance Assistants who came sometime back to educate the children and parents that we must wash hands with soap after using the toilet and if soap is unavailable we can use ashes. Currently, we haven't started using the ash because it is difficult but we still encourage them to wash hands using the buckets after using the toilet. Others wash hands at the borehole before they buy any food but the actual program is what we have planned to do in a few days to come. Head Teacher, Mangochi District

Additionally, many schools experience a lack of support from both the community and students, as many are not aware of the benefits of HWWS. Children are also not accustomed to HWWS in their homes, and they lack knowledge about disease prevention and have inadequate handwashing facilities.

"I think we can deal with this in several ways. First of all, this should not only be a responsibility for teachers. Parents should be involved as well. For example, the way you have come here you can also go into the communities to sensitize people that they are supposed to wash hands after using the toilet. The message has to reach out to parents and chiefs as well. If the parents and chiefs are well informed of the practice and here at school teachers also teach pupils that same thing I think it can work out because pupils will learn it at school and find the same at home." Head Teacher, Salima District 
Theft of water buckets and soap was also identified as a significant barrier to handwashing behavior. In all three districts, school children and the wider community have been involved in stealing soap and buckets left in handwashing facilities or toilets at school, and schools struggle to replace these items regularly. Likewise, buckets are not sturdy, and tend to be multi-purpose, which impacts their durability. When buckets break frequently, schools are often unable to replace them in a timely fashion.

"The challenge we face is sometimes when you put the soap there you find out that someone has taken it or someone has broken the bucket and the water has been poured on the ground. Even though we are encouraging them to wash hands with soap they find it difficult because the buckets are broken and are inadequate. And sometimes we lack soap.” Head Teacher, Nkhatabay District

"However, even if the soap is available it would be difficult for us to take care of it since we will be in class teaching and some clever pupils may take the soap to their homes. We also have goats around which do eat soap and can pick it up, unlike pigs which don't eat soap.” Head Teacher, Salima District.

"After receiving the buckets there were no major challenges, however, the only challenge was that there were a few and the pupils would use the same buckets for mopping the classrooms. You know what happens with kids, some could drop them and they quickly got broken.” Head Teacher, Mangochi District

In addition to theft, security of the toilets was also found to be an important issue. Many of the schools are situated along a road, and since the toilets are not secured after school hours, the community is able to access and use them. Even when doors are added with locks, termites eat through the wood and the doors are quickly destroyed. The wider community is not motivated to keep the toilets clean, and thus they become very dirty very quickly.

"The other problem that we encounter is that our school is along the road and the toilets are close to the road and also there is not enough security. We also have a problem with termites that when we put a door, it does not last long before it is destroyed and so people using the road end up using the toilets and you know how drunk people can be, they just defecate everywhere and we struggle with the school pupils to clean and these are all the problems we face with hygiene all because we are along the road." Head Teacher, Nkhatabay District

"We have also constructed some urinals for the boys. Now the problem we have is that the urinals are near the road side, so although we make sure to keep the urinals clean when we come in the morning we find some people have not used them properly, others have defecated on the urinals. Since toilets were constructed by the roadside, people passing by just use them anyhow. So that's a great challenge because here in the rural areas most children do not have shoes and go in there without shoes." Head Teacher, Mangochi District

In all three districts, availability of water is a persistent challenge. Schools have varying sources of water and in some locations there are boreholes, while in others there are fresh water sources where school children are required to fetch water. In order to get sufficient water for the day, schools must leverage school children to assist, however, this takes students away from their classes. 
"Our main challenge is water. We don't have a water source here at school so we fetch water from a distant place from here. Therefore, the main problem is that we involve the children so much to fetch water from a place that is far from the school. It's almost 500 meters from here to where the borehole is and they have to struggle against community members to fetch the water. As a result it takes them longer to come back since they have to wait for others to draw water first." Head Teacher, Salima District

"We have a borehole down there but currently it is not working. The pupils are fetching drinking water from far down that side. There is one down there and the other is also far that side. Head Teacher, Mangochi District.

Ability

School administrators and teachers agreed students were not knowledgeable about the benefits of handwashing with soap or the link between soap use and disease prevention. Furthermore, some students do not have access to toilets at home, and so they were never taught proper bathroom etiquette in terms of keeping the toilet clean, or handwashing with soap after going to the toilet.

"The other challenge is that most of the pupils do not use the toilets, they urinate behind the toilets and when they come from such places they don't wash their hands. It seems most of the pupils don't use toilets at home and they are used to such behavior. So even if we encourage them to do that they don't like it." Head Teacher, Mangochi District.

Several strategies to improve students' handwashing behavior emerged including sanitation and hygiene lessons and handwashing demonstrations. Sanitation and hygiene is incorporated into the lesson plans in each of the three school districts. For example, in the Salima district, younger children are taught the importance of handwashing through music with the aim of assisting them to remember the handwashing message. Songs about handwashing are also used during times when most students are using the toilets, that is, tea and lunch breaks, to remind them to wash their hands after using the toilet.

"We teach the pupils some lessons to do with sanitation. Like for younger children we teach them through music so they can know what we are talking about." Head teacher, Salima District.

In both the Nkhatabay and Mangochi districts, school children learn about handwashing with soap in Life Skills courses, designed to encourage handwashing behavior after using the toilet and before eating.

"We encourage these pupils especially in a lesson called Life Skills. In classes like Standard 3 and 4 we call it 'Luso La Moyo Wabwino' and there is a topic called Health Life and we advise them that there are health practices like washing hands and taking a bath. But here at school we encourage them to wash hands before they eat food, also to wash hands with soap after using the toilet. These are important things." Teacher, Mangochi District.

Demonstrations on proper handwashing are also used to help experiential learners to practice handwashing and understand how to clean their hands thoroughly. This also allows students to learn about the importance of washing their hands on a regular basis, and in particular at critical times in the day such as before eating and after toileting. To reinforce handwashing behavior, schools incorporate rules around handwashing and eating. 
"Firstly, we explain to them the importance of the practice because they just can't do it after being taught. So we explain to them every day and sometimes we even demonstrate to the pupils so that they can see what we are talking about. We educate them first before they start practicing it. They have to wash hands before eating, for instance these days we have porridge for them. So before they take their meals they have to wash hands." Teacher, Salima District

School management and staff reported schools actively engage students in educational activities to promote handwashing behaviors to increase their motivation to perform HWWS. Student leaders were also found to be an important influence on student handwashing behavior norms. School management acknowledged the need to make HWWS a habit over time, but stressed simultaneously that if students do not have access to handwashing facilities including clean water and soap, they are unable to participate in the behavior. However, despite best practices such as experiential learning and incorporating habitual cues (e.g. jingles) the major challenge for schools remains a lack in infrastructure to provide school children with adequate facilities to practice proper HWWS. Additionally, school administrators highlighted the lack of support and infrastructure for practicing handwashing behavior at home was a barrier to school children adopting HWWS. Practical implications of our findings are discussed hereafter.

\section{Practical implications}

The purpose of this paper was to provide formative insight, which is a key criterion for social marketing program design (Andreasen, 2002; Kubacki \& Rundle-Thiele, 2016). These insights will be used to provide an evidence base for the development of social marketing programs aiming to increase school children's HWWS behavior. Furthermore this research has answered calls to go beyond individual level approaches to social marketing and selfreport methods in social marketing by employing a mix of approaches including observations and interviews to enable triangulation of data sources.

The findings from this study offer a range of implications for social marketing practice. The results show across all districts, rates of handwashing at baseline were extremely low. This is due to many schools lacking facilities to enable HWWS behavior. This indicates upstream level social marketing is required to provide the supporting infrastructure and resources to enable HWWS behaviour to be undertaken by the target audience, in this case school children. For example, examination of opportunity revealed a lack of access to proper handwashing facilities or when there are handwashing facilities available, there is no access to clean water to enable students to use the handwashing facilities. The lack of availability of soap was another significant barrier for school children to undertake handwashing with soap behavior. Several reasons for this lack of availability of soap were cited including lack of funding and theft. This indicates that the price and place strategies need to be carefully considered to increase opportunity when developing social marketing programs aiming to improve handwashing with soap behaviours. In the context of place, handwashing facilities should be constructed in convenient locations close to either the classroom or toilets or ideally close to both. Our findings demonstrate that the closer the handwashing facility to the classroom or toilet, the more likely the school children are to wash their hands. In the context of price, improvements are also required to school and community infrastructure to facilitate the adoption of the behaviour, for example, toilet facilities should be secured so they are not used or damaged by the general public. 
Many of the schools were situated along public roads and toilet facilities were not secured after school hours which led to community members accessing and using the facilities without adequately cleaning them. This indicates location and security of facilities is an important influence on HWWS behaviour amongst school children and should be considered when designing HWWS social marketing programs. Sustainable funding options are therefore required for the development of handwashing stations and continued supply of soap are required before any social marketing program can commence. To this end, leveraging an upstream social marketing approach, Malawian schools would benefit from increased financial support from both government and non-government organisations to increase HWWS opportunity and enable schools to provide adequate infrastructure and the resources necessary to facilitate regular HWWS behavior.

In terms of motivations, school administrators and teachers reported that students were not supported to perform HWWS behaviour at home which may be due to lack of knowledge on the benefits of handwashing or simply a lack of available facilities and resources to enable HWWS behaviour to be undertaken. At the midstream social marketing level, given the importance of social and cultural norms for behavior adoption in social marketing programs (Parkinson et al., 2016) it may be useful to engage in a whole of community approach (Brown et al., 2006; Stokols, 1996; Van Acker et al., 2011). This would include motivating the local community to participate in the HWWS social marketing program thus allowing a change in handwashing culture to take place.

At the downstream social marketing level, individual factors should be targeted including exchange, segmentation, product, price and place (Andreasen, 2002). Exchange, one of the key social marketing benchmark criteria (Andreasen, 2002; Almosa et al., 2017) is an important consideration when developing social marketing programs. Using the results of this study, schools can be clustered into segments (Rundle-Thiele et al., 2014) based on school children's ability levels including current hand washing knowledge, attitudes and actual hand washing behavior. Based on the segments identified, an exchange offering can be developed in the form of specific programs (product) for each of these segments which leverage their current levels of motivation. For example, those schools where there is currently no infrastructure and no hand washing behavior need to have facilities installed and supplies of soap purchased prior to educational efforts taking place. This should be integrated with current education programs for staff, parents and students on the health benefits of HWWS and the correct process of HWWS. For schools where the appropriate infrastructure is already in place, products in the form of supporting activities that encourage students to engage in HWWS and reinforcement strategies to sustain the behavior over time should continue to be implemented. This will provide the motivation, opportunity and ability for students to generate new HWWS habits and behaviors over time. Students can then potentially become change agents for HWWS behavior by reinforcing handwashing behavior within their home environment contributing to the achievement of the national objectives to reduce diarrhea and thus leading to improved health and wellbeing for communities in Malawi.

\section{Limitations and future research}

The study has some limitations. First, it only reports the findings on a small sample of primary schools in Malawi. Further research is required which examines a larger number of schools to give a more thorough understanding of the current state of play with regards to infrastructure and HWWS behaviors of school children in Malawi. Future research should explore school infrastructure differences between rural and urban settings. Future research may also consider interviewing children regarding their motivation, opportunity and abilities 
to gain additional formative insights to inform future downstream social marketing efforts. The recommendations from this study which are informed by the MOA framework need to be implemented and tested empirically to enable a broader generalisation of the findings for the development of social marketing programs.

\section{References}

Almosa, Y., Parkinson, J., \& Rundle-Thiele, S. (2017). A socio-ecological examination of observing littering behaviour. Journal of Nonprofit \& Public Sector Marketing.

Andreasen, A. R. (2002). Marketing social marketing in the social change marketplace. Journal of Public Policy \& Marketing, 21(1), 3-13.

Bhutta, Z. A., Das, J. K., Walker, N., Rizvi, A., Campbell, H., Rudan, I., \& Black, R. E. (2013). Interventions to address deaths from childhood pneumonia and diarrhea equitably: what works and at what cost? The Lancet, 381(9875), 1417-1429.

Binney, W., Hall, J., \& Oppenheim, P. (2006). The nature and influence of motivation within the MOA framework: implications for social marketing. International Journal of Nonprofit and Voluntary Sector Marketing, 11(4), 289-301.

Binney, W., Hall, J., \& Shaw, M. (2003). A further development in social marketing: application of the MOA framework and behavioral implications. Marketing Theory, 3(3), 387-403.

Blanton, E., Ombeki, S., Oluoch, G. O., Mwaki, A., Wannemuehler, K., \& Quick, R. (2010). Evaluation of the role of school children in the promotion of point-of-use water treatment and handwashing in schools and households-Nyanza Province, Western Kenya, 2007. The American Journal of Tropical Medicine and Hygiene, 82(4), 664671.

Bowen, A., Ma, H., Ou, J., Billhimer, W., Long, T., Mintz, E., .. . Luby, S. (2007). A clusterrandomized controlled trial evaluating the effect of a handwashing-promotion program in Chinese primary schools. The American Journal of Tropical Medicine and Hygiene, 76(6), 1166-1173.

Brennan, L., Binney, W., Parker, L., Aleti, T., \& Nguyen, D. (2014). Social marketing and behaviour change: Models, theory and applications: Edward Elgar Publishing.

Brown, W. J., Mummery, K., Eakin, E., \& Schofield, G. (2006). 10,000 Steps Rockhampton: evaluation of a whole community approach to improving population levels of physical activity. Journal of Physical Activity and Health, 3(1), 1-14.

Carins, J. E., Rundle-Thiele, S. R., \& Fidock, J. J. (2016). Seeing through a Glass Onion: broadening and deepening formative research in social marketing through a mixed methods approach. Journal of Marketing Management, 32(11-12), 1083-1102.

Dholakia, U. M., \& Bagozzi, R. P. (2002). Mustering motivation to enact decisions: How decision process characteristics influence goal realization. Journal of Behavioral Decision Making, 15(3), 167-188.

Domegan, C., McHugh, P., Devaney, M., Duane, S., Hogan, M., Broome, B. J., ... \& Piwowarczyk, J. (2016). Systems-thinking social marketing: conceptual extensions and empirical investigations. Journal of Marketing Management, 32(11-12), 11231144.

Ejemot-Nwadiaro, R. I., Ehiri, J. E., Arikpo, D., Meremikwu, M. M., \& Critchley, J. A. (2015). Hand washing promotion for preventing diarrhea. The Cochrane Library. 
EMIS Section, (2013). Malawi Department of Education Planning, Ministry of Education, Science and Technology, accessed from www.fedomamalawi.org/public/themes/Fedoma/.../education_statistics_2012.pdf

Freeman, M. C., Greene, L. E., Dreibelbis, R., Saboori, S., Muga, R., Brumback, B., \& Rheingans, R. (2012). Assessing the impact of a school-based water treatment, hygiene and sanitation programme on pupil absence in Nyanza Province, Kenya: a cluster-randomized trial. Tropical Medicine \& International Health, 17(3), 380-391.

Glewwe, P., \& Jacoby, H. G. (1995). An economic analysis of delayed primary school enrollment in a low income country: the role of early childhood nutrition. The Review of Economics and Statistics, 156-169.

Hoyer, W. D., \& MacInnis, D. J. (1997). Consumer Behavior. Boston. NY: Houghton Mifflin Company.

Humphrey, J. H. (2009). Child undernutrition, tropical enteropathy, toilets, and handwashing. The Lancet, 374(9694), 1032-1035.

Jamison, D. T., Breman, J. G., Measham, A. R., Alleyne, G., Claeson, M., Evans, D. B., . . . Musgrove, P. (2006). Disease control priorities in developing countries.

Jasper, Christian, Le, Thanh-Tam, \& Bartram, Jamie. (2012). Water and sanitation in schools: a systematic review of the health and educational outcomes. International Journal of Environmental Research and Public Health, 9(8), 2772-2787.

Jaworski, B. J., \& MacInnis, D. J. (1989). Marketing jobs and management controls: toward a framework. Journal of Marketing Research, 406-419.

Joshi, A., \& Amadi, C. (2013). Impact of water, sanitation, and hygiene interventions on improving health outcomes among school children. Journal of Environmental and Public Health, 2013.

Koopman, J. S. (1978). Diarrhea and school toilet hygiene in Cali, Colombia. American Journal of Epidemiology, 107(5), 412-420.

Kubacki, K., \& Rundle-Thiele, S. (2016). Formative Research in Social Marketing: Innovative Methods to Gain Consumer Insights: Springer.

Lincoln, Y. S., \& Guba, E. G. (1985). Naturalistic Inquiry. Beverly Hills, Calif: Sage Publications.

Loewenstein, G., Price, J., \& Volpp, K. (2016). Habit formation in children: evidence from incentives for healthy eating. Journal of Health Economics, 45, 47-54.

MacInnis, D. J., Moorman, C., \& Jaworski, B. J. (1991). Enhancing and measuring consumers' motivation, opportunity, and ability to process brand information from ads. Journal of Marketing, 32-53.

Malawi Ministry of Health. (2011). Malawi Health Sector Strategic Plan 2011 - 2016. Malawi.

Martin, P. Y., \& Turner, B. A. (1986). Grounded theory and organizational research. The Journal of Applied Behavioral Science, 22(2), 141-157.

Morel, K. P., Poiesz, T. B., \& Wilke, H. A. (1997). Motivation, Capacity and Opportunity to Complain: Towards a Comprehensive Model of Consumer Complaint Behavior. ACR North American Advances.

National Economic Council, Malawi. (1998). Vision 2020 The long-term development perspective. Malawi.

National Statistical Office (NSO), \& ICF Macro. (2010). Malawi Demographic and Health Survey 2010. Zomba, Malawi, and Calverton, Maryland, USA:NSO and ICF Macro.

Park, C. W., \& Mittal, B. (1985). A theory of involvement in consumer behavior: Problems and issues. Research in Consumer Behavior, 1(3), 201-232. 
Parkinson, J., Gallegos, D., \& Russell-Bennett, R. (2016). Transforming beyond self: Fluidity of parent identity in family decision-making. Journal of Business Research. 69(1), 110-119.

Parkinson, J., Schuster, L., \& Russell-Bennett, R. (2016). Insights into the complexity of behaviours: the MOAB framework. Journal of Social Marketing, 6(4), 412-427.

Perkins, H. (2003). The social norms approach to preventing school and college age substance abuse: A handbook for educators, counselors, and clinicians. Jossey-Bass.

Piper, J. D., Chandna, J., Allen, E., Linkman, K., Cumming, O., Prendergast, A. J., \& Gladstone, M. J. (2017). Water, sanitation and hygiene (WASH) interventions: effects on child development in low-and middle-income countries. The Cochrane Library.

Rosen, L., Manor, O., Engelhard, D., Brody, D., Rosen, B., Peleg, H., . . Z Zucker, D. (2006). Can a handwashing intervention make a difference? Results from a randomized controlled trial in Jerusalem preschools. Preventive Medicine, 42(1), 27-32.

Rundle-Thiele, S. R. (2009). Social gain: Is corporate social responsibility enough? Australasian Marketing Journal, 17(4), 204-210.

Rundle-Thiele, S., Kubacki K., Tkaczynski, A., \& Parkinson, J. (2014). Using two-step cluster analysis to identify homogeneous physical activity groups. Marketing Intelligence and Planning, 33(4), 522-537.

Stokols, D. (1996). Translating social ecological theory into guidelines for community health promotion. American Journal of Health Promotion, 10(4), 282-298.

Talaat, M., Afifi, S., Dueger, E., El-Ashry, N., Marfin, A., Kandeel, A., . . . El-Sayed, N. (2011). Effects of hand hygiene campaigns on incidence of laboratory-confirmed influenza and absenteeism in schoolchildren, Cairo, Egypt. Emerging Infectious Diseases, 17(4), 619.

UNICEF. (2012). UNICEF Water, Sanitation and Hygiene Annual Report 2011. New York: UNICEF.

Van Acker, R., De Bourdeaudhuij, I., De Cocker, K., Klesges, L. M., \& Cardon, G. (2011). The impact of disseminating the whole-community project'10,000 Steps': a RE-AIM analysis. BMC Public Health, 11(1), 3.

Verplanken, B., \& Wood, W. (2006). Interventions to break and create consumer habits. Journal of Public Policy \& Marketing, 25(1), 90-103.

Watson, J. A., Ensink, J. H., Ramos, M., Benelli, P., Holdsworth, E., Dreibelbis, R., \& Cumming, O. (2017). Does targeting children with hygiene promotion messages work? The effect of handwashing promotion targeted at children, on diarrhea, soiltransmitted helminth infections and behaviour change, in low-and middle-income countries. Tropical Medicine \& International Health.

Willmott, T., \& Parkinson, J. (2017). Motivation, opportunity, and ability: Understanding new habits and changes adopted for weight management. International Journal of Consumer Studies, 41(3), 291-298.

World Bank. (2017). The World Bank in Malawi accessed from: http://www.worldbank.org/en/country/malawi/overview

World Health Organization. (2008). Disease and injury country estimates, Burden of Disease 2008. Geneva: WHO; 2004. 